\title{
Literatura como projeto
}

Rodrigo da Silva Cerqueira ${ }^{1}$

Definir-se intelectualmente, definir o próprio fazer intelectual, é "um dos móveis centrais que impulsionam a concorrência entre os diversos tipos de produtores", agentes em constante disputa no campo, e que lutam, em especial, "pela monopolização da autoridade de legislar em matéria cultural", como lembra Sergio Miceli (2001, p. 247). As construções sobre a própria obra, as tomadas de posição mesmo extraliterárias que almejam definir o trabalho de um produtor, podem, assim, ser lidas como parte de um jogo cujo principal objetivo é situar-se de forma destacada no campo, legislando quando possível sobre o fazer artístico, mas, em primeira ordem, posicionando-se no rol de destaque das obras e dos nomes que nesse espaço se constitui. Refazer criticamente esse jogo requer, porém, atenção não só aos movimentos declarados, mas também ao exame das sutilezas, aos passos menos evidentes e que, por assim o serem, contêm disputas mais efetivas até acerca das noções de valor que gravitam pelo campo, são produzidas por ele.

Um caso instigante para esse olhar particular sobre a arte é o exame da atuação de Luiz Ruffato no campo literário brasileiro durante as duas últimas décadas. Ainda que tenha publicado dois livros entre 1998 e 2000, Ruffato se insere efetivamente na cena literária do país em 2001, com o romance eles eram muitos cavalos. O livro, talvez uma das grandes obras da literatura brasileira deste século, inclui o nome do autor no campo não só pelas premiações recebidas, mas sobretudo pela repercussão crítica que pode ser medida pelo sem número de dissertações de mestrado e teses de doutorado a ele dedicados, além dos vários ensaios e artigos sobre a narrativa que passam a ser produzidos e circular pelo meio acadêmico, habitat da crítica literária de hoje.

A repercussão de eles eram muitos cavalos faz com que Ruffato projete seu nome, oferecendo-lhe capacidade de movimentação mais autônoma, maior espaço para se posicionar enquanto

\footnotetext{
${ }^{1}$ Doutor em letras e professor EBTT do Colégio Militar de Juiz de Fora, Juiz de Fora, MG, Brasil. (Dorcid.org/0000-0003-2256-2832. E-mail: rodrigoscerq@gmail.com
} 
intelectual e configurar novas tomadas de posição tanto ficcionais como extraliterárias. É nesse cenário que o escritor, no período entre 2005 e 2011, publica Inferno provisório, pentalogia cujo objetivo - amplamente anunciado por ele em entrevistas e depoimentos seria o de rever a história brasileira na segunda metade do século XX sob a perspectiva proletária. O exame da trajetória de Ruffato a partir da publicação de seu projeto literário, em especial o papel dos textos públicos através dos quais ele se posiciona ao posicionar sua obra, permite investigar as disputas e aproximações que o autor vai estabelecendo, a forma que encontra para alocar-se no rol de destaque da ficção brasileira atual.

Desde o início da publicação de Inferno provisório em 2005, o projeto é tratado pelo autor como o resultado de um amplo planejamento. Trata-se, segundo ele, de uma espécie de obra de vida, concebida desde sempre e concluída a custo. Essa característica é reforçada pela própria construção da pentalogia, resultado da combinação das narrativas que formavam seus dois primeiros livros de contos com outras inéditas, cuja nova ordem daria corpo a um romance em mosaico. Além disso, ainda seguindo as palavras do escritor, Inferno provisório construir-se-ia em virtude de intensa pesquisa estética e consolidaria a voz de Ruffato como dissonante na literatura brasileira contemporânea, acima de tudo pela estetização do imaginário da classe baixa conduzida por sua ficção. Em entrevista ao site Livre Opinião, já com todos os cinco volumes de Inferno provisório publicados, Ruffato articula o momento pós-eles eram muitos cavalos e as oportunidades que se abriam ao novo projeto nestes termos:

Para mim, escrever sobre São Paulo foi uma espécie de pedágio que eu queria pagar para poder compreender um pouco o lugar onde eu estava vivendo, além de exercer um exercício formal para escrever um projeto que era o meu projeto de vida literário, o "Inferno Provisório". Eu já tinha claro esse projeto no ponto de vista do conteúdo, mas eu não sabia como executá-lo, então tive que escrever Eles eram muitos cavalos para compreender que tipo de linguagem eu podia utilizar e só depois que o terminei e publiquei tive condições de realmente sentar e produzir o "Inferno Provisório", que me demandou 15 anos. Escolhi escrever sobre a camada da classe média baixa porque sou dessa origem. Minha mãe foi lavadeira de roupas e meu pai foi pipoqueiro. Eu fui operário têxtil, logo em seguida 
torneiro mecânico e quando eu comecei a ler literatura brasileira com mais interesse descobri que essa camada baixa não estava sendo representada, então minha decisão foi no sentido político. Eu me dei como tarefa tentar representar a camada social baixa na literatura brasileira (Ruffato, 2013, s.p.).

A exposição sobre o processo de construção da pentalogia revela duas dimensões da forma como o trabalho de Ruffato é por ele inserido no campo. De um lado, o processo de pesquisa estética necessário para a construção da obra; de outro, a necessidade de se construir uma representação da classe baixa a partir do ponto de vista interno, devedor da própria biografia do autor, cujas experiências de algum modo facultariam um olhar verdadeiro sobre o imaginário estilizado em sua ficção - perspectiva consolidada no discurso da Feira Internacional do Livro em Frankfurt de 2013. Essas duas dimensões, contudo, articulam-se no posicionamento do próprio autor diante dos demais agentes do campo de produção, em especial a partir da construção de um diálogo efetivo com a crítica, talvez a maior responsável pela legitimação de uma experiência artística.

$\mathrm{O}$ anúncio de eles eram muitos cavalos enquanto etapa do Inferno provisório, por exemplo, elabora uma espécie de coerência no trabalho do escritor, como se tudo fizesse parte de um planejamento estrito, sem quaisquer lacunas, ao passo que a caracterização do romance de 2001 como um pedágio tente direcionar as próprias atenções do campo para a pentalogia. Entretanto, relembrar a todo o momento a construção de eles eram muitos cavalos na fatura de Inferno provisório parece também uma necessidade de o autor se justificar perante os legisladores literários, aqueles com o poder, como lembra Pascale Casanova (2002, p. 39), "de dizer o que é literário e o que não é, de traçar os limites da arte literária", como se possível fosse relembrar-lhes seu valor e os porquês desse valor, redirecionando o capital anterior para a nova empresa.

Essa relação ganha em complexidade se se observa como o primeiro romance do escritor é recebido pela crítica literária e de que maneira Ruffato parece dialogar com essa recepção, em especial através dos textos públicos que definem sua obra e seu nome. Karl Erich Schøllhammer, em textp publicado em Uma cidade em camadas, reunião de ensaios voltados à análise do primeiro romance de Rufffato - o que ratifica o peso do livro diante dos "legisladores" -, 
aponta a construção em eles eram muitos cavalos de uma nova gramática narrativa a partir dos usos e desusos do real para a construção dos fragmentos que dão forma ao romance. Para o pesquisador, os textos da cidade fazem o urbano incluir-se na ficção seja na transcrição de "santinhos" de Santo Expedito, recomendações para pedidos, conselhos para preservação de casamentos, um cardápio, uma carta, listas de empregos ou dos títulos de livros numa estante, a lista de dez CDs, anúncios de contato amoroso, anúncios de garotas de programa, ou na enumeração dos objetos de uma copa. Esses fragmentos possuem uma natureza ambígua por serem signos da cidade incluídos entre os signos da ficção, obtendo-se, assim, uma concretude objetiva, articulados como objetos de uma bricolagem textual, "coisas" coletadas na rua, índices referenciais da cidade que participam da montagem do texto com o poder de arraigar ou indexar o texto no real (Schøllhammer, 2009, p. 82-83).

Por sua vez, Andrea Saad Hossne vê, na construção dos fragmentos e nas atualizações dos elementos da realidade para a elaboração narrativa, fundamentos de eles eram muitos cavalos, em especial pelo propósito social do romance de discutir os códigos da cidade e imprimi-los na forma literária. Segundo ela, por tratar a "degradação urbana" como tema, Ruffato tem de pôr em prática certo "procedimento de acumulação", que implicaria "numa formalização problemática [...] do ponto de vista, do foco narrativo, da figura mesma do narrador em prosa" (Hossne, 2007, p. 19); devido a esses aspectos, o livro remeteria "ao romance parecendo mesmo sua ruína" (Hossne, 2007, p. 39).

Porém, as chaves com que a crítica analisa, e legitima, eles eram muitos cavalos não são muito distintas daquelas com que o próprio autor defende seu primeiro romance e insere o projeto Inferno provisório no campo literário. eles eram muitos cavalos é constantemente articulado pelo escritor enquanto experiência estética calcada na porosidade característica das manifestações artísticas contemporâneas, para cuja feitura foi necessária a adoção de um procedimento e acumulação e atualização dos signos da cidade, como defende o próprio Ruffato num artigo intitulado "Da impossibilidade de narrar": 
Flanar por ponto de ônibus e velórios, locais onde houve chacinas e supermercados, templos evangélicos e conjuntos habitacionais populares, favelas e prisões, hospitais e bares, estádios de futebol e academias de boxe, mansões e hotéis, fábricas e lojas, shopping centers e escolas, restaurantes e motéis, botequins e trens... Recolher do lixo livros e eletrodomésticos, brinquedos e cardápios, santinhos e calendários, jornais velhos e velhas fotografias, anúncios de simpatias e de resolução de problemas financeiros... Compreender que o tempo em São Paulo não é paulatino e sequencial, mas sucessivo e simultâneo. Assumir a fragmentação como técnica (as histórias compondo a História) e a precariedade como sintoma - a precária arquitetura do romance, a precária arquitetura do espaço urbano. A violência da invisibilidade, a violência do não-pertencimento, a violência de quem tem que construir uma subjetividade num mundo que nos quer homogeneamente anônimos. A impossibilidade de narrar (Ruffato, 2010, p. 33-34).

A apropriação dos signos da cidade enquanto elementos do tecido narrativo, a adoção de uma "precária arquitetura" que faça surgir um romance "parecendo mesmo sua ruína", diz mais sobre o diálogo profícuo não só entre a obra e o repertório crítico contemporâneo, mas principalmente entre a forma como o autor insere seu trabalho no campo de produção e os caminhos pelos quais esse mesmo trabalho pode ou não ser aceito por aqueles que detêm o poder de dizer o que é literário e de atribuir-lhe maior ou menor valor. O discurso de Ruffato sobre eles eram muitos cavalos conservase, assim, sempre muito próximo do que a crítica escolhe destacar sobre o romance, e esse movimento oferece a possibilidade de ler os futuros posicionamentos do autor, sobretudo aqueles destinados à inserção do projeto Inferno provisório no campo literário.

Obra de objetivos claros, o projeto iniciado em 2005 é constantemente articulado por seu autor como obra devedora do repertório estético adquirido pela feitura de eles eram muitos cavalos. Num depoimento escrito originalmente à época do lançamento de $O$ livro das impossibilidades, quarto volume da pentalogia, Ruffato define como um momento de impasse o período posterior à publicação de seu primeiro romance, e que seria resolvido de forma peculiar na construção do Inferno provisório: 
Publicado Eles eram muitos cavalos encontrei-me num impasse: havia proposto uma reflexão sobre o "agora", mas talvez necessitasse compreender antes "como chegamos onde estamos". Então, comecei a elaborar o Inferno provisório, uma "saga" projetada para cinco volumes (dos quais quatro já publicados, a saber: Mamma, son tanto felice, O mundo inimigo, Vista parcial da noite e $O$ livro das impossibilidades), que tenta subsidiar essa inquietação, discutindo a formação e evolução da sociedade brasileira a partir da década de 1950, quando tem início a profunda mudança do nosso perfil socioeconômico, de um modelo agrário, conservador e semifeudal para uma urbanização desenfreada, desarticuladora e pós-industrial, e suas consequências na desagregação do indivíduo. [...] Só que não compreendo uma reflexão sobre essa cisão sem que sejam colocados em xeque os próprios fundamentos de gênero. Do meu ponto de vista, para levar à frente um projeto de aproximação da realidade do Brasil de hoje, torna-se necessária a invenção de novas formas, em que a literatura dialoga com outras artes (música, artes plásticas, teatro, cinema etc.) e tecnologias (Internet, por exemplo), problematizando o espaço de construção do romance, que absorve onivoramente a estrutura do conto, do ensaio, da crônica, da oralidade (Ruffato, 2008, p. 322).

A capacidade de absorção do romance, o procedimento de acumulação que o concebe como peça também de problematização do romanesco, pode ser associada às observações sobre o próprio eles eram muitos cavalos, que oferecem ao livro e, consequentemente, a seu autor, um lugar particular no campo, posição na qual se inserem aqueles produtores cuja literatura busca questionar os limites da fatura literária através, em especial, da porosidade característica das manifestações artísticas contemporâneas. Se o Inferno provisório só é possível após eles eram muitos cavalos, a construção da pentalogia como romance (um romance construído por narrativas independentes, um não romance, que desafiaria as características básicas do gênero) pode ser entendida também como uma forma que o autor tem de jogar com as exigências do campo literário, os parâmetros críticos que este erige para a legitimação de seu trabalho ficcional.

Mas o valor é "movente", a todo momento "contestado e discutido" (Casanova, 2002, p. 162), e o nome de um produtor só permanece se se mantém em constante negociação com o campo, 
inaugurando novas disputas que consolidam seu lugar específico nesse espaço de produção ou renovam esse lugar, reformulam seu próprio local de enunciação. Ao Inferno provisório não basta, pois, reeditar eles eram muitos cavalos; é necessário qualquer traço de singularidade que o faça ser lido, e recebido, de forma distinta da obra anterior, ainda que aproveitando seus antigos méritos. Talvez por isso, em seu processo de inserção, a pentalogia venha acompanhada de novos posicionamentos de Luiz Ruffato, numa aparente tentativa de construir para si um lugar específico de fala que o diferencie dos demais produtores literários.

Seguindo tal busca, as considerações sobre a reformulação do discurso romanesco trabalhada no projeto que objetiva narrar a história do Brasil sob perspectiva proletária dialogam agora com o ponto de vista da ficção, em relação estreita com a trajetória pessoal do autor. Não raro, Ruffato justifica sua pentalogia pela necessidade de falar sobre a própria origem, numa aproximação entre obra e vida que acaba o posicionando como porta-voz do trabalhador urbano na literatura. Exemplo característico desse movimento particular é a introdução do já citado depoimento “Até aqui, tudo bem!", um texto de cunho autobiográfico em que Ruffato se define como artista:

$\mathrm{Na}$ mesa do meu escritório, de onde avisto os prédios do bairro da classe média alta de Higienópolis, do outro lado da Avenida Pacaembu, em São Paulo, há um porta-retrato. Nele, uma fotografia embaçada registra uma estranha composição: em primeiro plano um menino, trajando uma curta blusa de flanela, um desajeitado short e um sujo par de chinelos de dedo, tristes e assustados olhos semifechados. Pousadas em seus ombros magros, duas mãos femininas; ao lado, parte de uma perna de calça e uma barriga, que se advinha em breve proeminente, indica a existência de um homem (marido das mãos femininas, talvez). Assentada sobre o braço da mulher, uma outra mão. Pela composição das sombras, deduz-se a tarde, e pelas roupas, o final de inverno. Assim a foto sobre a mesa: o menino surge de corpo inteiro, mas os outros três personagens são inidentificáveis - falta-lhes o rosto, página em branco onde se imprime nossa individualidade, nossa singularidade, nossa história, enfim. Todo o meu esforço como escritor tem sido o de tentar recompor essa imagem. O menino, identifico-o, sou eu, aos cinco ou seis anos de idade. 
Mas quem são os outros três personagens que, numa tarde de inverno para sempre perdida, imobilizaram-se para o olhar amador de alguém por detrás da máquina fotográfica? Quais são seus nomes, de onde vieram, onde estarão agora, o que fizeram de suas vidas, foram felizes? Do menino, sei eu - e, curiosamente, é o que menos importa. Mas, e todos aqueles que sucumbiram, sem voz e sem nome, e que a História registrará apenas nas lápides de humildes cemitérios que a borracha do tempo apagará? E os outros, que nem mesmo a morte resgatará do anonimato? (Ruffato, 2008, p. 317).

A ficção surge como necessidade pessoal, na busca por uma reconstrução da própria história que, por fim, é também a história da classe baixa brasileira, relegada ao emprego módico ou ao subemprego, distante da posse dos bens materiais ou simbólicos e, portanto, longe de qualquer redenção no término de sua caminhada. Atrelar à própria literatura uma fotografia pessoal é, portanto, um movimento político, para cuja leitura tornar-se-ia necessária a identificação do autor enquanto uma espécie de emissor autorizado, a quem a trajetória pessoal referendaria como voz autêntica, ciente dos problemas e imaginário da classe baixa, pois estes desenham também sua origem social.

Esse movimento de aproximação da ficção com a trajetória pessoal pode, inclusive, explicar algumas escolhas de Ruffato na tessitura do depoimento. Ao destacar os prédios "de classe média alta do bairro de Higienópolis" como distantes de seu escritório, o escritor está marcando um lugar de fala muito particular, numa antítese que daria forma a seu trabalho com a escrita e, logo, sua literatura como fruto de um outro mundo, distante daquelas pessoas, daquela condição econômica, daquela forma de ver e abordar a realidade. Ao mesmo tempo, a demarcação do objetivo pessoal que o leva a escrever, a ideia de reconstruir a história de quem é apagado pela História (reflexão essencialmente benjaminiana), marca a classe a que diz pertencer o autor de forma muito evidente e em oposição a outros grupos que, por não dividirem o mesmo horizonte de expectativas, não teriam capacidade de compreender seus dilemas peculiares.

A mesma reflexão é desenvolvida noutros textos públicos, procurando confirmar o escritor como porta-voz da classe baixa, enquanto busca oferecer para sua literatura uma existência 
autônoma no campo de produção. Na já mencionada entrevista ao site Livre Opinião, Ruffato tenta definir um padrão literário nacional para, ao mesmo tempo, situar-se em oposição a ele:

A Literatura fica representando a si mesma e a classe média é a que estuda, portanto, ela estará sempre se representando. Se você pensar em termos mais amplos, a Literatura Brasileira, muitas vezes, fica bastante limitada a um olhar da classe média sobre a própria classe média. É inevitável que isso aconteça por conta da questão que temos uma educação formal no país de péssima qualidade. É quase impossível alguém que não é da classe média alta ter uma educação formal suficiente para se tornar escritor. Eu sou uma exceção (Ruffato, 2013, s.p.).

Proclamar-se como exceção é constituir-se em diferença no campo. Um morador do bairro de Perdizes, também de "classe média alta", jornalista formado e de importante trajetória na imprensa, escritor profissional - e premiado - desde o início da década de 2000, não pode, porém, situar-se de forma tão distinta dos demais produtores literários. Remontar à infância, à origem, é, portanto, tentar ocupar um outro posto, cuja articulação - sempre muito bem demarcada - garantiria tanto a singularidade quanto a sobrevida do artista. Assim, dá-se maior espaço ao ponto de vista interno a fim de que o projeto caminhe por si só, tentando articular novos códigos para análise, outros pontos que, destacados, vinculam-se estritamente à construção do projeto e ao valor que ele mesmo - sendo inserido pelo autor - vai buscando erigir.

Nesse aspecto, um traço de Inferno provisório que ilustra bem as possíveis tensões produzidas entre a obra (e, consequentemente, seu autor) e o campo encontra-se na própria articulação do projeto enquanto obra de fôlego, com extensão e objetivos claramente definidos, estendendo ao escritor a condição de porta-voz da classe baixa. $\mathrm{Na}$ cena literária contemporânea, uma obra que retoma a tradição realista dos grandes ciclos épicos, com a pretensão de, lembrando Arnold Hauser, "sondar o homem e auscultar o mundo" (1998, p. 730), soa anacrônica, mas esse anacronismo pode ter algo de programático, construindo uma disputa particular com o repertório crítico atual e os valores que o mesmo desenvolve e sustenta enquanto formas de ler a literatura do presente. 
No, talvez, primeiro ensaio que buscava traçar um panorama da ficção brasileira no início do século XXI, Flávio Carneiro defende uma espécie de "espírito de época" contemporâneo que seria articulado pela literatura. Segundo ele, embora detentores de múltiplos projetos estéticos, os escritores atuais encontrar-se-iam num olhar geral sobre a realidade e as possibilidades literárias caracterizado por certo deslocamento:

Deslocamento das ideologias estabelecidas - esquerda e direita para uma postura múltipla, multifacetada, herança talvez dos movimentos de contracultura. Deslocamento dos grandes projetos para os projetos particulares, formulados numa perspectiva menos pretensiosa, em que o posto de missionário, porta-voz do novo, é preenchido pelo cidadão comum, preocupado menos com rupturas radicais do que a convivência pacífica com o próprio presente (Carneiro, 2005, p. 18-19).

A aposta na multiplicidade como principal sintoma da literatura contemporânea, a negação das grandes empresas, redireciona $\mathrm{o}$ papel do escritor e do próprio fazer literário; por ora, não haveria espaço para o intelectual identificado com causas específicas, ocupando o "posto de missionário", identificado com aqueles que julgaria representar. Essa inexistência, todavia, implica num movimento um pouco mais amplo, desenhado pela quase erradicação da literatura de cunho realista, disposta a questionar as construções sociais brasileiras. É a direção para a qual parecem apontar os argumentos de Beatriz Resende, ao definir três evidências da produção literária contemporânea, ou da consolidação de um "sistema literário com conceitos próprios do que é literatura":

1. A escrita de uma nova literatura democrática, que aposta na instituição de um sistema literário partilhado, que reconhece novas subjetividades e novos atores no mundo da cultura, e na reconfiguração do próprio termo literatura.

2. O deslocamento das narrativas do espaço local, nacional. $\mathrm{O}$ rompimento com a tradição literária de afirmação da língua, da nação, dos valores culturais nacionais. Em vez da literatura que fala do Brasil, que usa a cor local como valor (rentável) de troca, a literatura que busca se inserir, sem culpa, no movimento dos fluxos globais. 
3. A ruptura com a tradição realista da literatura, não pelo uso de recursos ou formatos próprios da ficção não realista, como o absurdo ou real-imaginário latino-americano, mas pela apropriação do real pelo ficcional de formas diversas, com a escrita literária rasurando a realidade que, no entanto, a incorpora. $\mathrm{O}$ documental e o ficcional podem conviver na mesma obra, como acontece em outras criações artísticas contemporâneas (Resende, 2014, p. 14).

Não deixa de ser curiosa a leitura de uma produção que se deseja "democrática", mas que de uma ou outra maneira parece excluir certas formas de se fazer ficção daquilo que poderia ser classificado como literatura. Parece defender Resende uma espécie de ruptura constante, movimento que implicaria na caracterização da literatura de base referencial, vinculada à tradição realista, como algo ultrapassado, impossível de se relacionar com os novos tempos. $\mathrm{O}$ "sistema literário com conceitos próprios", assim, possuiria diretrizes muito bem definidas, instituindo valor a certos procedimentos estéticos, como os ligados à problematização das fronteiras entre verdade e ficção e ao questionamento da própria forma literária, e relegando a segundo plano quaisquer movimentos na direção de uma literatura mais "nacional" ou afeita ao Realismo.

Diante desse cenário, quando se posiciona como uma espécie de porta-voz literário da classe baixa, munido de uma obra aos moldes de um ciclo épico, de objetivo e olhar demarcados, Luiz Ruffato se definiria em oposição ao campo, criando para si uma nova posição, reforçando seu nome a partir do ineditismo, da diferença em relação aos demais produtores nesse espaço inseridos. Assim, assumir a postura de "missionário", realizar e posicionar um grande projeto em tempos de incompletude, buscar a partir da ficção problematizar a formação da sociedade brasileira sob o ponto de vista da classe baixa constituiriam estratégias de reversão das próprias expectativas do campo.

No entanto, é necessário situar essa reversão e entendê-la dentro da própria trajetória do autor no campo, as posições por ele ocupadas e os espaços que lhe são oferecidos para se movimentar. Após a recepção de eles eram muitos cavalos, reforcemos, os caminhos oferecidos a Luiz Ruffato são os de um autor ciente das possibilidades de sua literatura questionar os gêneros tradicionais e buscar, a partir da renovação formal, construir a ficção. Assim, ao 
posicionar Inferno provisório, ainda que em tensão com certos códigos do espaço de produção, o escritor parece tentar se manter na posição já ocupada, conquanto busque no mesmo movimento fundar uma nova posição para si, procedimento que pode ser lido nas diversas definições que o autor faz da pentalogia, como esta, articulada em entrevista a Luciano Trigo, logo após a publicação de Domingos sem deus (2011), romance de fechamento do projeto:

O meu ideal seria uma mescla de Balzac e Faulkner. Por mais absurdo que possa parecer, esses dois autores, de épocas e culturas tão diferentes, caminharam na mesma direção. A grande diferença é que Balzac constrói um mundo urbano em ascensão e Faulkner um mundo rural em ruínas... Mas as preocupações de ambos são as mesmas (Ruffato, 2011, s.p.).

Rejeitar o norte oferecido pelo campo para as futuras movimentações seria rejeitar a possibilidade de se manter no clube seleto dos autores de destaque. Noutro ponto, articular para si uma nova posição dependeria também de um reconhecimento das possibilidades de ação dentro do próprio espaço de produção, diante de seus legisladores. Assim, unir o perfil do escritor missionário como Balzac ao do autor revolucionário como Faulkner é, ao mesmo tempo, situar-se em semelhança e diferença ao campo. Esse duplo movimento nos facultaria concluir que a reversão das expectativas desse espaço por Ruffato é acompanhada por movimentos de aproximação muito intensos com o repertório cultivado pelos legisladores literários, um diálogo efetivo entre autor e crítica em termos do reconhecimento de quem detém o poder para dizer o que é ou não é arte, o que deve ou não ser apreciado. É nesse jogo de avanços e recuos, concordâncias e desvios, que o escritor buscaria situar-se, reconhecendo caminhos que lhe oferecessem legitimação e veredas pelas quais pudesse criar outras formas de ser lido.

Não é possível dizer, porém, que se trate de um plano arquitetado de forma totalmente consciente pelo autor; a lucidez, como lembra Pierre Bourdieu, é "sempre parcial", e sua análise uma "questão de posição e de trajetória no campo", variando "segundo os agentes e segundo os momentos" (1996, p. 306). Também não é possível afirmar que essa seja a única maneira de ler a inserção do projeto Inferno provisório no campo literário brasileiro e seu papel na trajetória de Luiz Ruffato. Há, aqui, uma possibilidade de análise 
sobre os caminhos possíveis de serem adotados por um escritor em seu campo de produção, buscando inserir-se no rol de destaque que se constrói nesse espaço, dialogando com os parâmetros de avaliação e legitimidade que ele cria para se estruturar.

\section{Referências}

BOURDIEU, Pierre (1996). As regras da arte: gênese e estrutura do campo literário. Tradução de Maria Lúcia Machado. São Paulo: Companhia das Letras.

CARNEIRO, Flávio (2005). No país do presente: ficção brasileira no início do século XXI. Rio de Janeiro: Rocco.

CASANOVA, Pascale (2002). A república mundial das letras. Tradução de Marina Appenzler. São Paulo: Estação Liberdade.

HAUSER, Arnold (1998). História social da arte e da literatura. Tradução de Álvaro Cabral. São Paulo: Martins Fontes.

HOSSNE, Andrea Saad (2007). Degradação e acumulação: considerações sobre algumas obras de Luiz Ruffato. In: HARRISON, Marguerite Itamar (Org.). Uma cidade em camadas: ensaios sobre o romance Eles eram muitos cavalos, de Luiz Ruffato. Vinhedo: Horizonte. p. 18-42.

MICELI, Sergio (2001). Intelectuais à brasileira. São Paulo: Companhia das Letras.

RESENDE, Beatriz (2014). Possibilidades da escrita literária no Brasil. In: FINAZZI-AGRÓ, Ettore; RESENDE, Beatriz (Org.). Possibilidades da nova escrita literária no Brasil. Rio de Janeiro: Revan. p. 9-24.

RUFFATO, Luiz (2008). Até aqui, tudo bem! (Como e porque sou romancista - versão século 21). In: MARGATO, Izabel; GOMES, Renato Cordeiro. Espécies de espaço: territorialidades, literatura, mídia. Belo Horizonte: Editora da UFMG. p. 317-324.

RUFFATO, Luiz (2010). Da impossibilidade de narrar. In: ASSISES INTERNATIONALES DU ROMAN, 4., Lyon, França, 24-30 maio. Disponível em: <https:/ / bit.ly/2vD8WC9>. Acesso em: $1^{\mathrm{o}}$ jun. 2015.

RUFFATO, Luiz (2011). Ficção de Luiz Ruffato permanece fiel à classe operária. Entrevista a Luciano Trigo. Máquina de Escrever, [S.l.], 9 dez. Blog. Disponível em: <https://glo.bo/2Ovs0Jo>. Acesso em: 10 maio 2014. 
RUFFATO, Luiz (2013). Eu me dei como tarefa tentar representar a camada social baixa na literatura. Livre Opinião, [S.1.], 20 dez. Entrevista. On-line. Disponível em: https:/ / bit.ly/2B4jaAH>. Acesso em: $1^{\mathrm{o}}$ jun. 2015.

SCHØLLHAMMER, Karl Erik (2007). Fragmentos do real e o real do fragmento. In: HARRISON, Marguerite Itamar (Org.). Uma cidade em camadas: ensaios sobre o romance Eles eram muitos cavalos, de Luiz Ruffato. Vinhedo: Horizonte. p. 68-76.

Recebido em 30 de setembro de 2017.

Revisado em 14 de maio de 2018.

Aprovado em 30 de maio de 2018.

\section{resumo/abstract/resumen}

\section{Literatura como projeto}

Rodrigo da Silva Cerqueira

Este trabalho analisa a inserção do projeto Inferno provisório e a trajetória de seu autor, Luiz Ruffato, no campo literário brasileiro. Pentalogia de objetivos sempre bem definidos pelo autor em entrevistas e depoimentos, o Inferno provisório surge como um projeto, mas pode ser analisado sob outro viés quando se esmiúça as posições que o escritor vai ocupando no campo. Assim, são examinados textos públicos em que o autor posiciona sua obra e seu nome na tentativa de identificar e analisar as relações que este estabelece para tentar, de algum modo, situar seu trabalho no espaço de produção.

Palavras-chave: campo literário, crítica, movimentos, Luiz Ruffato.

\section{Literature as a project}

Rodrigo da Silva Cerqueira

This article analyses the insertion of Luiz Ruffato's project Inferno provisório and his trajectory in the Brazilian literary field. With its objectives always demarcated by his author in interviews, Inferno provisório emerges as a project, but that could be analyzed under another perspective, if the positions that the writer occupies in the field are taken into account. Thus, the essay examines public texts in which the author positions his work and his name in an attempt to identify and analyze the relationships that he establishes. The essay's attempt to place his work in the space of production.

Keywords: literary field, criticism, movements, Luiz Ruffato. 


\section{Literatura como proyecto}

Rodrigo da Silva Cerqueira

Este trabajo analiza la inserción del proyecto Inferno provisório y la trayectoria de su autor, Luiz Ruffato, en el campo literario brasileño. Pentalogía de objetivos siempre bien definidos por el autor en entrevistas y testimonios, Inferno provisório surge como un proyecto, pero puede ser analizado bajo otro sesgo si las posiciones que el escritor va ocupando en el campo son desmenuzadas. Así, se analizan textos públicos en que el autor posiciona su obra y su nombre en el intento de identificar y analizar las relaciones que éste establece para intentar, de algún modo, situar su trabajo en el espacio de producción.

Palabras clave: campo literário, crítica, movimentos, Luiz Ruffato. 